\title{
ARTICLE
}

\section{"Stepping in and Stepping out": Enabling Creative Third Spaces Through Transdisciplinary Partnerships}

\author{
*Giedre Kligyte ${ }^{a}$, Alex Baumber ${ }^{a}$, Mieke van der Bijl-Brouwer ${ }^{b}$, Cameron Dowd $^{a}$, Nick \\ Hazell ${ }^{a}$, Bem Le Hunte ${ }^{a}$, Marcus Newton ${ }^{a}$, Dominica Roebuck ${ }^{a}$, and Susanne Pratt ${ }^{a}$ \\ ${ }^{a}$ Faculty of Transdisciplinary Innovation, University of Technology Sydney, Australia \\ ${ }^{\mathrm{b}}$ Faculty of Industrial Design Engineering, Delft University of Technology, Netherlands \\ Contact: giedre.kligyte@uts.edu.au
}

\section{ABSTRACT}

This article explores how transformative higher education approaches can be fostered through an integration of the concepts of third space, Students as Partners (SaP), and transdisciplinarity in practical contexts. We describe a collaborative enquiry that engaged staff and students in a reflexive dialogue centred on the concepts of mutual learning, liminality, emergence, and creativity as enacted in the curriculum of a transdisciplinary undergraduate degree, the Bachelor of Creative Intelligence and Innovation (BCII) at the University of Technology Sydney in Australia. The key insights that emerged through this enquiry were: third spaces in curriculum can be enabled but not constructed, all parties need to embrace uncertainty and a mutual learning mindset, and that "stepping in and out" of such fluid liminal spaces can stimulate creativity. Based on our experience and exploration, we offer some practical recommendations to those seeking to create similar enabling conditions for third spaces in their own undergraduate programs.

\section{KEYWORDS}

liminality, students as partners, third space, transdisciplinary, creativity

This article explores how synergies between the concepts of third space, Students as Partners (SaP), and transdisciplinarity can lead to transformative higher education practices (see Figure 1). Originating from different theoretical and practical domains, these three perspectives have been applied in a variety of contexts to address diverse ethical, political, or societal concerns. These concepts and their associated practices share a common focus on bringing together stakeholders as equals in non-hierarchical interactions, with the purpose of mutual learning from diverse knowledges and perspectives. 
Figure 1. Features of the concepts of third space, SaP, and transdisciplinarity

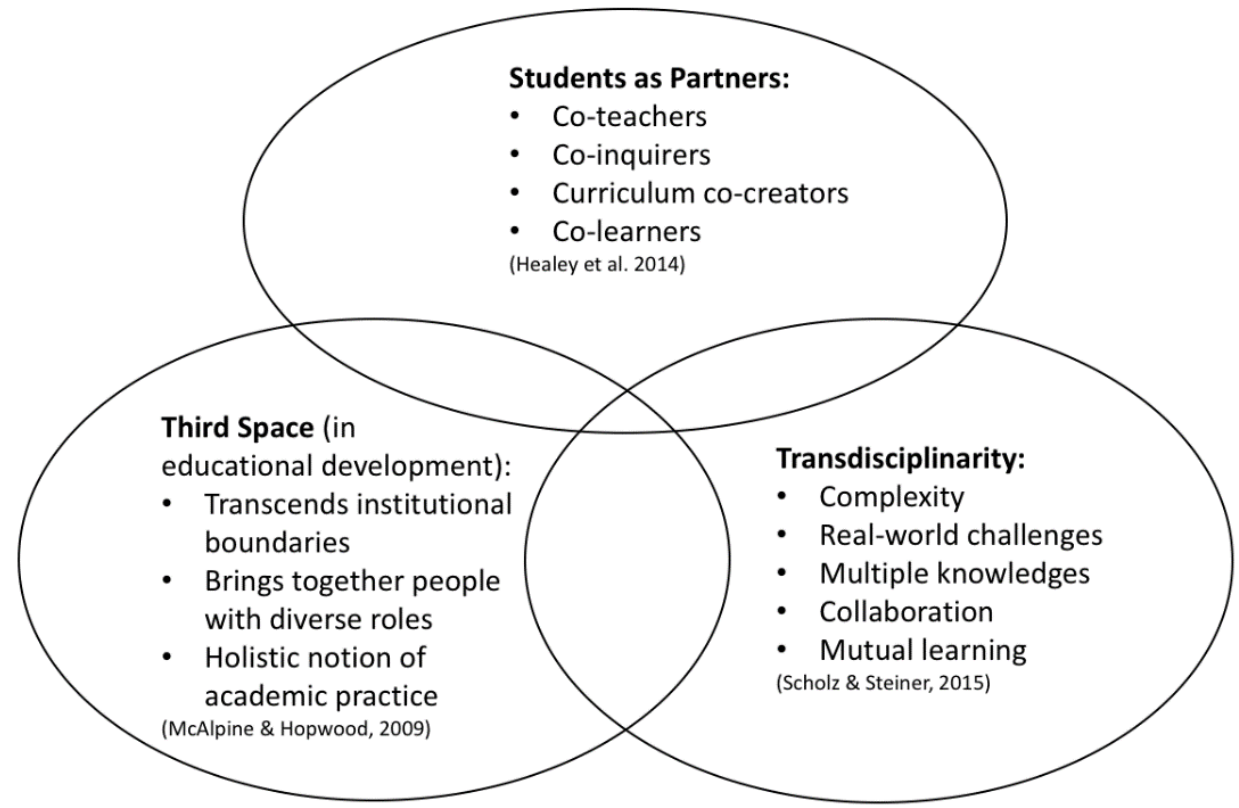

SaP approaches have gained prominence over the past decade in higher education research and practice (Matthews, Dwyer, Hine, \& Turner, 2018). This growing interest in SaP is partly driven by the desire to frame learning in higher education in more relational terms, challenging the "student as consumer" discourse (Matthews, 2016; Matthews, Cook-Sather, \& Healey, 2018; Matthews, Dwyer, et al., 2018). In this paper, we explore the ways that scholarly work on third spaces (e.g., Gutiérrez, 2008; Soja \& Hooper, 1993; Whitchurch, 2012), in conversation with the SaP literature, could strengthen the argument about the transformative potential held in SaP approaches. As we will demonstrate, higher education curriculum can accommodate "a transformative space where the potential for an expanded form of learning and the development of new knowledge are heightened" Gutiérrez (2008, p. 152). Such third spaces are not at the centre of power, nor are they in the margins. This in-betweenness allows third spaces to become sites of "radical openness" that can challenge either/or dichotomies of the dominant culture (Soja \& Hooper, 1993, p. 195), such as self/other, expert/non-expert, male/female, white/black, and teacher/student. An emphasis on fluidity and openness aligns third space with SaP, as they both share a focus on enabling new relations and knowledges to emerge. The importance of emergence is also important in the third conceptual lens we apply-transdisciplinarity-which allows us to further enrich the possibilities entailed in SaP and third space approaches

Our use of the term "transdisciplinarity" follows Manderson's (1998) proposition that "transdisciplinarity examines a particular site or sites of interest without a particular disciplinary strategy in mind" (p. 66). In contrast to interdisciplinarity, where methods are shared across disciplines, transdisciplinarity strives to move beyond disciplinary frameworks (Klein 2010). ${ }^{1}$ It involves: (a) addressing complex real-world challenges, (b) valuing multiple knowledge types, (c) collaborating with diverse stakeholders, and (d) mutual learning (Polk \& Knutsson, 2008; Scholz \& Steiner, 2015). By attaching importance to local, practical, and contextual knowledges alongside disciplinary expertise, transdisciplinary practices challenge existing power structures. For example, Scholz and Steiner (2015) argue that people who act Kligyte, G., Baumber, A., Bijil-Brouwer, M., Dowd, C., Hazell, N., Hunte, B., Newton, M., Roebuck, 6 D., \& Pratt, S. (2019). "Stepping in and stepping out": Enabling creative third spaces through transdisciplinary partnerships. International Journal for Students as Partners, 3(1). 
within a system on a daily basis (e.g., students in a learning system) are experts on the contexts in which they operate. Integrating transdisciplinary and SaP approaches allows us to further question power relationships implicit in traditional educational contexts.

In this article, we explore how third spaces have emerged through our attempts to engage students as partners in educational practices in the Bachelor of Creative Intelligence and Innovation (BCII) degree program, a recently introduced transdisciplinary undergraduate degree at the University of Technology Sydney in Australia. Transdisciplinary principles are incorporated into the BCII's double-degree design, whereby students undertake short intensive BCll subjects concurrently with their "core degree" (e.g., in business, science, communications, design, etc.) each summer and winter for three years. Their fourth and final year is spent entirely on the BCII with a dedicated studio space to work on projects set by industry partners and related to the students' own passions.

This paper uses the three conceptual lenses of third space, SaP, and transdisciplinarity to examine the learning and teaching strategies within the BCll final-year curriculum. Our experimentation ranged from an open-ended assessment task in which students were invited to contribute to the $\mathrm{BCll}$ community, to providing students with opportunities to codesign the curriculum, to an invitation to set rules for their own studio space. Through the confluence of the three abovementioned conceptual domains, and a process of mutual learning involving staff and students, we have come to better understand the educational, personal, and societal benefits of spaces in curriculum that are open rather than institutionally pre-determined.

\section{BACKGROUND}

SaP approaches aim to position students as active rather than passive participants in their learning. Partnerships create opportunities for transformative learning for students, staff, and whole institutions, which is achieved through process- rather than outcomeorientation and authentic engagement among all parties (Healey, Flint, \& Harrington, 2014). Thus, reciprocity has been identified as one of the key characteristics of SaP approaches (Healey et al., 2014). Participants in reciprocal partnerships may play different roles and derive different benefits provided that there is equity in the relationship (Cook-Sather \& Felten, 2017).

Mercer-Mapstone et al. (2017) highlight some of the dominant ways in which SaP has been explored to date. This includes a tendency for SaP studies to focus on student-teacher rather than student-student or student-industry partnerships, and for positive outcomes such as trust-building and enrichment of learning opportunities to be reported more often than negative outcomes such as increased vulnerability or power imbalances. However, it is unknown whether this reflects broader experiences with student partnerships in higher education or just what authors have elected to write about (see Mercer-Mapstone et al., 2017). While SaP initiatives can challenge unequal power relationships and hierarchies implicit in educational contexts, they can also be hampered by institutional or societal structural issues. For example, SaP initiatives tend to be small-scale and extra-curricular (Mercer-Mapstone et al., 2017), potentially excluding students who are not able to dedicate time to these initiatives due to caring or other commitments (Healey et al., 2014; MercerMapstone et al., 2017).

Despite these shortcomings, it is well-documented that SaP practices can allow students, staff, and other partners to cross boundaries and step outside traditional roles 
(Matthews, Dwyer, et al., 2018). As such, they lend themselves to be examined through the conceptual lens of third spaces. A key dichotomy in higher education is that of teacher/student (Cook-Sather \& Alter, 2011; Cook-Sather, Matthews, Ntem, \& Leathwick, 2018). Thinking about SaP practices through third spaces can allow new interactions and possibilities to emerge unconstrained by these established roles.

While third spaces may allow for conventional hierarchies to be diminished, it should be noted that they are contested rather than neutral spaces and are inevitably affected by the power dynamics that surround them (Solomon, Boud, \& Rooney, 2006). Authors writing about third spaces in education highlight the challenges that such heterogeneous contexts pose to educators, including around purpose, inclusivity, and reciprocity. For example, Gutiérrez (2008) emphasises the difficulties of creating a shared vision of education in third spaces that recognises the diverse and unequal experiences of different stakeholders. Transdisciplinary approaches can allow for these factors to be considered through a reflexive process of mutual learning between multiple stakeholders (Scholz \& Steiner, 2015).

Liminality emerges as another important property of third spaces, as zones between culturally defined phases or states (Cook-Sather \& Alter, 2011) that can facilitate creativity and personal growth. Anthropologist Victor Turner describes the journey of initiations in tribal society as an immersion in liminality where those undergoing transition enter "a realm of pure possibility whence novel configurations of ideas and relations may arise" (Turner, 1967, p. 97). Similarly, Campbell's (1993) conceptualization of the hero's journey of discovery highlights the importance of liminality to individual transition and maturation. Drawing on anthropological framing, Cook-Sather \& Alter (2011) discuss the powerful transformative effects of educational encounters that take place in indeterminate states between otherwise defined roles.

A key challenge arising from conceptualising educational encounters through the lens of third space is the uncertainty that it entails. While mainstream educational discourses emphasise clarity, curriculum alignment, and measurable outcomes, third spaces invite educational experiences that resist such definitions. By posing emancipatory goals, third spaces raise challenging questions about the ownership or division of responsibility over "delivering" educational outcomes. Although not writing in the context of SaP, Biesta (2013) highlights the radical uncertainty that educators face by inviting students to take responsibility for their own learning. Drawing on Levinas' philosophy, Biesta (2013) argues that we cannot force responsibility upon others and that education must necessarily be thought of as a slow, frustrating, unpredictable, risky, and uncertain process. He invites educators to be open to emergence and indeterminate possibilities in which a mutuality of responsibility may emerge, instead of shying away from the frustrations and uncertainty implicit in educational encounters (Biesta, 2013).

The importance of mutuality in risk-taking is highlighted by Healey et al.'s (2014) proposition that student partnership is "both risky and enables taking risks" (p. 20). Similarly, Soja and Hooper (1993) describe the third space as a "risky place on the edge... but also with new possibilities" (p. 190). It is interesting to consider the generative importance of risk highlighted by these authors in the context of Mercer-Mapstone et al.'s (2017) findings that the majority of published research on SaP approaches reports on positive outcomes. Transdisciplinary approaches can help to understand the interplay between risk and opportunity in educational third spaces through a focus on complex systems in which uncertainty is pervasive, relationships are often non-linear in nature, and 
links between cause and effect may be unclear (Max-Neef, 2005; Scholz \& Steiner, 2015). Viewed through a transdisciplinary lens, educational encounters in third spaces can thus be understood as opportunities for adaptation, self-organisation, and emergence within the complex adaptive system that is higher education (Zepke, 2017).

\section{METHOD}

To consider how the concepts of SaP, third space, and transdisciplinarity can shed light on our practices within the $\mathrm{BCll}$, we formed a team consisting of six teaching staff and three fourth-year students. The teaching staff included the BCll Course Director, Fourth-Year Coordinator and coordinators of subjects across all four years of the program. The team did not include any industry partners, but did include one staff member with a background in the food industry who coordinated the fourth-year subject where students work on challenges set by industry partners.

We wanted to ensure that the process of co-authorship did not disadvantage team members who were less familiar with the conventions of academic research and writing. Therefore, we created a process of enquiry that incorporated what Werder, Thomas, Ware, and Skogsberg (2010) term "parlor talk," which positions co-authors as equals in a reflexive dialogue. To enable team members to contribute their experiences and insights more equitably, we drew on Labonté's (2011) work on "story groups." We began by taking turns to share examples of where we thought third spaces had emerged in the BCII. We then built on and extended these stories through several iterations, enacting a "reflection circle," in Labonté's terms. To ensure that all team members had equal opportunity to speak, we used a "talking object" (a roll of paper) that was passed from person to person to indicate that it was their "talking turn" (Itzchakov \& Kluger, 2017). The dialogue was structured according to five generative themes, within which group members shared stories of BCII third spaces. Each theme was allocated 10-15 minutes. These themes were:

- What are third spaces in the BCII?

- Relationships (between who? defined or emergent? reciprocal?)

- Purpose (why are we doing this? what is the purpose of education?)

- Betwixt and between (including liminality, uncertainty and risk)

- Emergence and creativity (what emerges in third spaces?)

The selection of generative themes was influenced by the following readings circulated prior to the dialogue session: the review of SaP literature by Mercer-Mapstone et al. (2017), Whitchurch's (2012) explanation of the third space concept in higher education, Biesta's (2015) paper on "good education," Cook-Sather and Alter (2011) on liminality in higher education, and Gutiérrez (2008) on the evolution of the third space concept.

By framing our enquiry as an open-ended dialogue between equals, we sought to create the conditions for a third space to emerge within the very process of writing this paper. In other words, we anticipated that our insights would unfold through this collaborative process rather than being pre-determined from the outset. Lastly, by taking a more conversational approach to our writing, we hoped that our contribution to this special issue would be more accessible to a diverse readership.

The following section of this article presents an edited version of our dialogue, as recorded by a note-taker while participants spoke. After the dialogue session, the transcript was edited by each team member to ensure it captured the meaning of what they said and 
to remove repetition. One team member absent due to illness added his thoughts during the editing stage.

The authors of this article were the participants in the dialogue and though we challenge the traditional teacher-student roles in our thinking and practice, we feel it is important to acknowledge the positions from which the following insights are spoken: Bem Le Hunte, Mieke van der Bijl-Brouwer, Alex Baumber, Giedre Kligyte, and Nick Hazell are staff within the BCll and Marcus Newton, Cameron Dowd, and Dominica Roebuck are students.

The concluding stages of writing this paper were particularly enlightening to the team, as they brought to the fore the unequal positionings of staff and students inherent to the academic authoring process. As highlighted in our literature review, we see the tendency for SaP research to represent a positive picture of partnerships that glosses over vulnerabilities and discontinuities as problematic. In our case, despite staff attempts to create a dialogic third space through a relatively contrived formal methodology, student co-authors independently organised their own meetings that were intentionally more casual and exploratory. Students met up to follow up on interesting points from our "formal" conversations, but then felt that staff would be interested in these "tangential" thoughts too. They put their insights into a framework they have been taught: an Ignorance Map. One of the students reflected that they never intended for this map to become part of the paper: "it was more about connecting with the staff in a way that was encouraged-even though it did make us feel slightly vulnerable. We felt we had a platform to speak, and be heard."

While staff asserted their expertise by taking responsibility for editing the final version of the draft for consistency, we felt that it was important to include the section produced by students without substantial editing as an instance of students claiming their voice through a dialogic process. This section appears at the end of this paper titled "Future Questions and Unknowns Posed by Students." We do not see this emergent trajectory of insights created by students as a failure of managing the power dynamics or an inability to create a truly inclusive space for dialogue in our partnership. To us, this is evidence of sufficient openness within our enquiry process for unexpected outcomes to emerge-precisely the type of selfauthorship that we aspire to animate in $\mathrm{BCll}$ students through our efforts to challenge power imbalances in education.

\section{THIRD SPACE REFLEXIVE DIALOGUE}

Bem: For me, third space in $\mathrm{BCll}$ is a journey that begins in first year and continues throughout the whole four-year degree. Because it is transdisciplinary, our type of third space is a confluence between disciplines -25 different core degrees. It is not static. It is always emergent as we don't know what will happen when those disciplines come together. On top of this, we have individuals and their journeys. It is a conceptual space-the liminality between epistemologies and ontologies, disciplines and individuals.

Marcus: Third space emerges from our transdisciplinary approach.

Giedre: Are we saying that third spaces aren't possible without transdisciplinarity?

Bem: I don't think so. What we and others are doing that is liminal is working at the bleeding edge. The space that we're hoping to evolve hasn't been created yet. We are pushing the boundaries and looking to create third spaces that are "betwixt and between" (Turner, 1967). We create the enabling conditions-for example, we continually engage with the view that knowledge is contestable. From the first year onwards we explore 
"mistake-ism"-mistakes that have driven innovation across the disciplines. And we introduce students to ignorance-mapping to explore unknowns.

Dominica: What Bem said about carrying your centre to the edge stuck with me.

Nick: When we get good at BCIl we get bad at it. It's a bit like start-ups. They start as amateurs and then they become professionals and then innovation seems to peter out. The moment we think we know what we're doing, we lose $\mathrm{BCll}$ or it becomes problematic.

Giedre: I'm curious about how we socialise students into the tradition of breaking the tradition by innovating, and enact these principles in teaching. According to Biesta (2015), it is not only what you say but how you say it that forms the curriculum.

Bem: It's also about modelling that it's okay to be in an uncertain space yourselfwe're doing something so new that we're all learning from each other.

Alex: Being comfortable with uncertainty is a key theme. The capstone subjects were designed to allow for emergence, but this also creates uncertainty around what projects students could do and whether they were making the "right" choices. As a teacher I also had to embrace uncertainty. How was I going to organise all of this? How would I find resources and support students when I didn't know what the projects would be or the size of the teams?

Cameron: Looking at it from a much higher level-what will the degree look like in five years' time? How can you keep the essence of BCll if we're dabbling in liminality and ambiguity for too long? But also, what happens if we professionalise it?

Marcus: The nature of this new degree has ambiguity built in. How can you write ambiguity into the structure of a degree?

Mieke: There is always a part that is structured, and then there is a part that is emergent. Someone I interviewed last week said that working in a complex space is like a dance between looking for patterns and structures, and looking for surprises and emergence.

Giedre: So, third space can be bits of the curriculum that are not pre-determined by the institution or teaching staff. In the fourth-year we experimented with open assessments that allowed students to create initiatives of any type and format. Students were invited to contribute to their cohort community, leave a legacy to future students, or bring their own assessment briefs. As a result, we have witnessed some amazing creations-games, art installations, nights of music and inspiration, fireside talks - these exceeded our wildest expectations, all crafted with much care and commitment. Could such assessments be thought about as third space if they are open to the unexpected?

Cameron: I completely agree-because they're so open-ended, and because they invite students to bring their own briefs (and their own selves), I've been able to carry my own "passion project" through BCll which has gone far beyond the educational setting.

Mieke: I also think third space in the BCII is about interaction between people who don't usually work together-industry partners, staff, and students-in different ways creating novel interactions.

Nick: The unlearning of the first three years prepares students' minds, attitudes, and relationships when students get thrown random problems, partners, and teammates in fourth year. It also takes industry partners out of their environment into this liminal space. They react to problems in a different way. The power imbalance goes away. 
Alex: Mercer-Mapstone et al. (2017) found most SaP studies look at relationships between students and teachers, but in BCII it's also very much student-student and studentindustry partners as well.

Mieke: Also, teacher to teacher relationships. In BCll they feel very different from other teacher interactions I have had before. We each bring such different perspectives and knowledges, and learn a lot together and from one another.

Alex: If teachers take on mutual learning-which is integral to transdisciplinarity-do we become students as well in a sense for the purposes of SaP?

Cameron: I've never really known what to call the staff. I don't see them as "teachers" or "lecturers" or even "mentors" in the traditional sense. When we're in our third space, our roles quickly melt away. We're placed in this environment where we must work togetheras partners - to get the most out of the experience and be our best selves.

Dominica: For me a classic example of third space-you're in the middle of a conversation and a tutor comes in and asks the right question. The conversation feels lifted. There is something about the quality of the questioning. There is vulnerability in their curiosity. They are able to step into the space with us. The curiosity and willingness to ask questions is important. Your roles fall away.

Giedre: We tend to think about relationships as give and take, a transaction. Yet thinking about what happens in the BCll through the lens of third space, it is less about the individuals who come together and more about what emerges between us all. Through third space we are all affected by everyone else-we are not separate beings anymore.

Dominica: In the teacher-student relationship, I feel as if I lose a sense of self and my role, but then the interaction ends and I return to the assessment and become a student again. I still need to be a student.

Mieke: I love the idea of losing a sense of self-social systems theory is about the whole being different than the sum of its parts. I feel that in this space the idea of losing a sense of self is very strong, also for me as a teacher. I have my own individual research projects I work on, and then I have this collective educational space, and I go back and forth between these "spaces." In this third space, it's much less about individuals.

Nick: Last semester I found it hard being a tutor and subject coordinator at the same time. I wasn't able to be in this third space the way I normally can as a tutor. I was getting stressed about coordination and you cannot immerse yourself in the problem space as you'd like to.

Marcus: There are many teachers or mentors available, not just one. This plays a role. We are inviting teachers into our problems and our learning. During industry projects, we were hesitant to approach you, Nick. We worked with others, though we would have liked to engage you more.

Nick: This is an interesting framing-l'm coming into your problem, so you're inviting me in. I'm a guest. It's not my problem that you are working on and it has never been.

Mieke: But as teachers we have an important facilitation role. It does not always work. I ran a session last week, but there did not seem to be the right energy in the room, and a lot of students were not engaged. Maybe because I was fully in a facilitation role and not a learning role. I wonder if third space requires specific expertise or attitude to facilitate and learn at the same time.

Bem: For me, being "betwixt and between" (Turner, 1967) isn't static, but a process or a journey. You have to get to this third space, you can't be in it permanently. Drawing on

Kligyte, G., Baumber, A., Bijil-Brouwer, M., Dowd, C., Hazell, N., Hunte, B., Newton, M., Roebuck, 12 D., \& Pratt, S. (2019). "Stepping in and stepping out": Enabling creative third spaces through transdisciplinary partnerships. International Journal for Students as Partners, 3(1). 
Van Gennep (2060), it's a type of ritual-a process of gaining trust with students and taking the willing on a journey. A metaphor from my meditation teacher is having a saffron cloth (meditation) that loses its colour when you go into the world. You need to come back to these spaces to re-invigorate the colour - to get that nurturing. For me, liminality and creative process are about being able to go back and forth between the conventional, ordinary world and this liminal creative immersive process-or third space-where you are continually finding your way and making discoveries.

Mieke: I love the idea of dipping the cloth in dye. Being in complexity is like being in the middle of the ocean, yet you reach another shore. Students go back to their core disciplines. We go back to our core work, as do our casuals and industry partners. You need a balance. You need to go back. Like inhaling and exhaling. You need both for breathing. This relates to the idea of being. What type of people do we want our students to become? Being mindful that each student is unique, we're also looking for attitudes such as humility or risk-taking.

Marcus: If you identified these attributes how would this negatively or positively affect the degree? Is the fact that they haven't been prescribed what allows them to emerge?

Giedre: Following Biesta's (2015) idea of subjectification, l'd say that it does not really matter what shape or type graduates become, but it is important that they take on the responsibility of becoming this person.

Bem: You have to trust that you're going to get somewhere in this process, like trying to keep a kite up in the air over four years. Somehow, I always knew it would happen, because I had trust in the process-however unknown it was at the outset.

Giedre: I agree. In many of our teaching experiments we also had to trust that students would rise to the occasion and they did. Biesta (2013) coins the term "the beautiful risk of education"-you don't know that students will step up to take responsibility over their learning but you have to trust that they will.

Dominica: It's refreshing to hear about the risks that teachers are taking. It makes me understand staff more. We are taking risks with you, not just completing assessments.

Alex: We probably don't do this enough. Sharing our vulnerabilities and the risks we're taking is part of being genuine partners. I would like to do it more but sometimes feel I need to look like I know what I'm doing.

Giedre: There is an art to it. Bem does it really well by maintaining a narrative of overall stability while at the same time destabilising aspects of thinking.

Nick: Risk and safety-the two things together. You need to have conditions that are nurturing and challenging at the same time because then people take bigger risks.

Alex: An idea from systems thinking is fast variables and slow variables. Slow variables build resilience, like the way a university system supports us and how Bem creates continuity and a sense of calm. Fast variables change quickly, like our industry challenges and short intensive subjects.

Giedre: Interesting, so for third spaces in education we must also think about the points of stability, it is not just about the unstable spaces. It is about stepping in and stepping out. 


\section{INSIGHTS ARISING FROM THE REFLEXIVE DIALOGUE}

\section{Value of third spaces in education}

Our dialogue revealed insights into how third spaces can contribute to the emergence of student agency and creativity in education and can reframe relationships between staff and students. The development of novel and creative responses to complex challenges is a key goal of the BCII, enabled by our deliberate attention to conditions that support emergence. This has been enhanced by the porous boundaries we have attempted to create between disciplines and fields, as well as between the curriculum and the broader environment in which industry partners, students, and staff interact. This permeability and liminality between different knowledges and realities is influenced by transdisciplinary thinking (Max-Neef, 2005), but also capitalises on the "degrees of freedom" that third spaces can offer outside established modes of working (McAlpine \& Hopwood, 2009, p. 159). Thus, we argue that transdisciplinary spaces in educational programs can bring together various tribes (or disciplines) in an atmosphere that Durkheim, Cosman, and Cladis (2001, p. 218) would describe as "collective effervescence" - a gathering with a profound exuberance that is generative, yet somehow inexplicable.

Throughout the $\mathrm{BCIl}$, students are encouraged to embrace the opportunities inherent in uncertain and liminal spaces to "progress a learning project in the face of uncertainty" (Kahn, 2014, p. 1009). The metaphor of a sea voyage is introduced in the first year and the destabilizing nature of a voyage into the unknown plays out through the degree. Through educational encounters, students are given ways to frame and understand liminal spaces so that this uncertainty becomes familiar. For example, students are encouraged to develop a taxonomy of unknowns and use ignorance as a "muse" (Kerwin, 1993, p. 176). They are introduced to over a hundred methods for tackling complex real-word challenges from across the disciplines and learn to be comfortable with the cognitive dissonance of not knowing the answers they seek. This habit of visiting liminal spaces, we argue, is something that could be more broadly embraced across all educational contexts to enable students to engage creatively with uncertainty.

From our dialogue, it was clear that third space learning experiences in the $\mathrm{BCll}$ have challenged the traditional student-teacher dichotomy in higher education. This blurring of the boundaries between teachers, students, and industry partners can lead to mutual learning, which we see as another important outcome of third space-like educational arrangements. A transdisciplinary perspective on mutual learning (Polk \& Knutsson, 2015) also presents an opportunity to create a more expansive notion of partnership, one that includes student-student and student-industry partnerships, which is relatively infrequent in SaP studies (Mercer-Mapstone et al., 2017). Furthermore, Cook-Sather et al.'s (2018) recent discussion of the SaP term itself highlights that naming only student participants in SaP may imply that staff retain the power in partnerships. The reciprocity encapsulated in transdisciplinary approaches, we argue, has the potential to decentre power relationships implicit in education and reframe the SaP concept to incorporate notions of "teachers as learners" and, as expressed by some of the student participants in our dialogue, "teachers as partners."

What does it mean for staff who wish to embrace a role as genuine partners and as mutual learners? In our experience, operating in the space "betwixt and between" (Turner, 1967) disciplines and fields has enabled us to be comfortable with dwelling on a groundless ground of liminality. In our dialogue, we discussed our efforts to maintain a sense of 
wonderment in our teaching and to avoid developing a formula for it, which risks closing off opportunities for emergent outcomes. For staff, this openness can be a perpetual source of inspiration and rejuvenation, as students produce previously unimagined responses to complex challenges. However, this requires staff, as well as students, to embrace uncertainty and be prepared to show vulnerability-revealing what you don't know rather than just what you do know. The relationships that emerge through such educational encounters, based on openness, vulnerability, trust, and shared responsibility, are an important outcome in their own right.

\section{Enabling and resisting conditions for the emergence of third spaces}

Following Gutiérrez's (2008) view that third spaces emerge, as well as Biesta's (2013) notion of radical uncertainty in the ways educational outcomes unfold and the influence of complexity thinking within transdisciplinarity (Max-Neef, 2005), we argue that transdisciplinary third spaces cannot be constructed or forced into being. Instead, we propose that they can emerge when the enabling practices and conditions are present. Such processes can be encouraged, tended to, and guided, but are usually spoilt if attempts are made to control them (Hasan, 2014). With this in mind, Figure 2 maps some of the enabling conditions for the emergence of third spaces that we have identified through our practice, reading, and dialogue.

\section{Figure 2. Enabling conditions and practices for educational third spaces in the BCII}

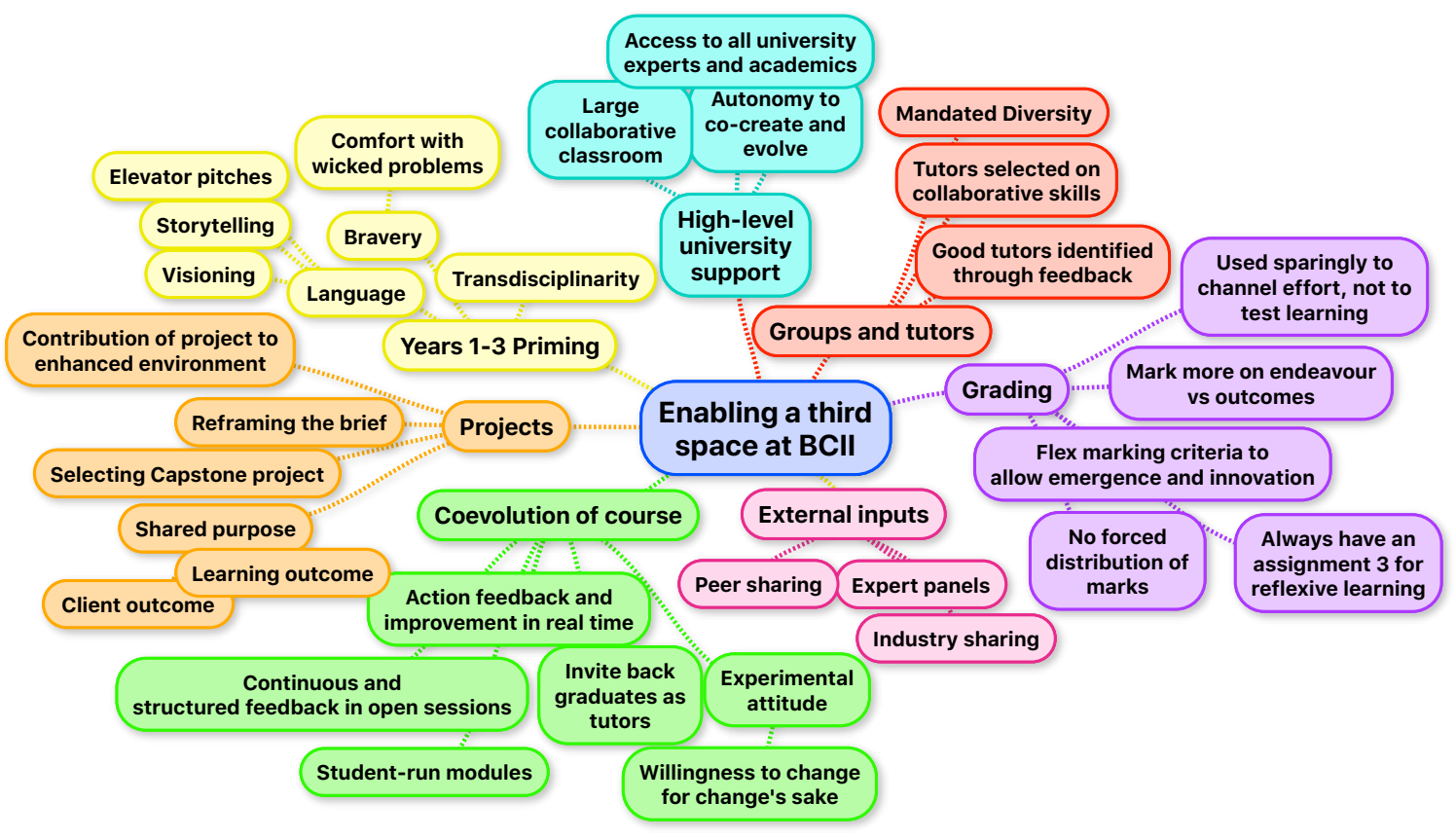

Many of the components in Figure 2 represent deliberate elements of curriculum design, such as the allocation of students into transdisciplinary teams based on their different core degrees, the use of reflexive learning assessment tasks, and the requirement that student teams engage with industry partners in reframing project briefs. However, other elements have emerged along the way, particularly through student feedback and involvement in co-design sessions, which have resulted in student-run sessions within the 
curriculum, peer sharing, and student-led decisions on how the studio space is used (i.e., with semi-permanent workspaces for each team and workshops rather than lectures).

It is important to highlight that the BCll enjoys high-level support within the university, which helps to overcome the institutional inertia that Whitchurch (2012) warns can hamper third spaces. This high-level support gives staff a mandate and the autonomy to co-create and evolve the degree in a novel and experimental way that is markedly different from other degrees. Furthermore, the early years of the degree prime students to become comfortable with uncertainty and liminality, develop reflexive practices, and work on shared projects across different disciplines. Principles of shared responsibility and mutual risktaking adopted by staff and students have created the conditions for trusting and reciprocal relationships to emerge. In particular, BCIl staff approach tutoring as a partnership with students, drawing on collaborative and facilitation skills rather than dispensing expertise. The focus on shared objects, such as team challenges, allows for a multiplicity of perspectives that stimulate fresh thinking and an openness to difference. Assessments are designed to encourage emergent rather than prescribed outcomes, in particular through reflexive knowledge-synthesis tasks and a contribution to the enhancement of the transdisciplinary community to which students, staff, and industry partners belong.

The resistances encountered in the $\mathrm{BCIl}$ are mainly related to structural and logistical aspects of organizing transformational educational experiences, including the necessity for some students to do paid work, lack of time, interruptions related to the rigidity of the institutional systems and processes, and the limitations posed by the physical spaces. Another area of contention and discomfort identified through our dialogue was the grading of assessments, with both staff and students feeling that the importance placed upon grades within the university system diminished the potential for the emergence of third spaces. We also saw that the ability of teaching staff to take risks and embrace uncertainty was undermined by institutional cultures of measurement and evaluation. Issues of inclusivity and equity were also raised and are explored further in the following section, which, as explained earlier, was written by student co-authors.

\section{FUTURE QUESTIONS AND UNKNOWNS POSED BY STUDENTS}

The transdisciplinary aspect of the $\mathrm{BCll}$ degree relies on a diverse ecosystem of students, teachers, industry partners, and institutional support. However, the selection process for this degree is very traditional and competitive by higher education standards, which could potentially prioritise "voices that are already privileged and engaged" (MercerMapstone et al., 2017, p. 17). As student authors, we questioned how more socio-economic and cultural diversity could be introduced into a typical BCII cohort. We explored the idea of regular, student-hosted workshops and co-design sessions for university groups, high school students, and the general public.

We also reflected on the predictable nature of recent projects, and the relationships with industry partners that prescribe them. We brainstormed decisive steps that could be taken to engage the cohort in a more diverse range of problem spaces and projects that challenge assumptions and enable new knowledge and experiences to emerge. For example, we agreed that there was a concentration of corporate projects, compared to the weaker presence of not-for-profit partners. We were interested in how investment in developing long-term relationships with such partners could introduce a mutually-beneficial learning experience, potentially triggering a deeper immersion into third space. We 
proposed inviting future partners (such as not-for-profits) into the BCll space to regularly participate in workshops, activities, and hackathons. We were interested in how this emphasis on relationship-forming could transform and enable the potentiality of third space. We also explored how this newfound emphasis on diversity could influence our perception and experience of a supposed third space. We continue to ask provocative questions in Figure 3, which is based on the Ignorance-Map model developed by the University of Arizona College of Medicine (Kerwin, 1993).

\section{Figure 3. Ignorance map developed by student authors}

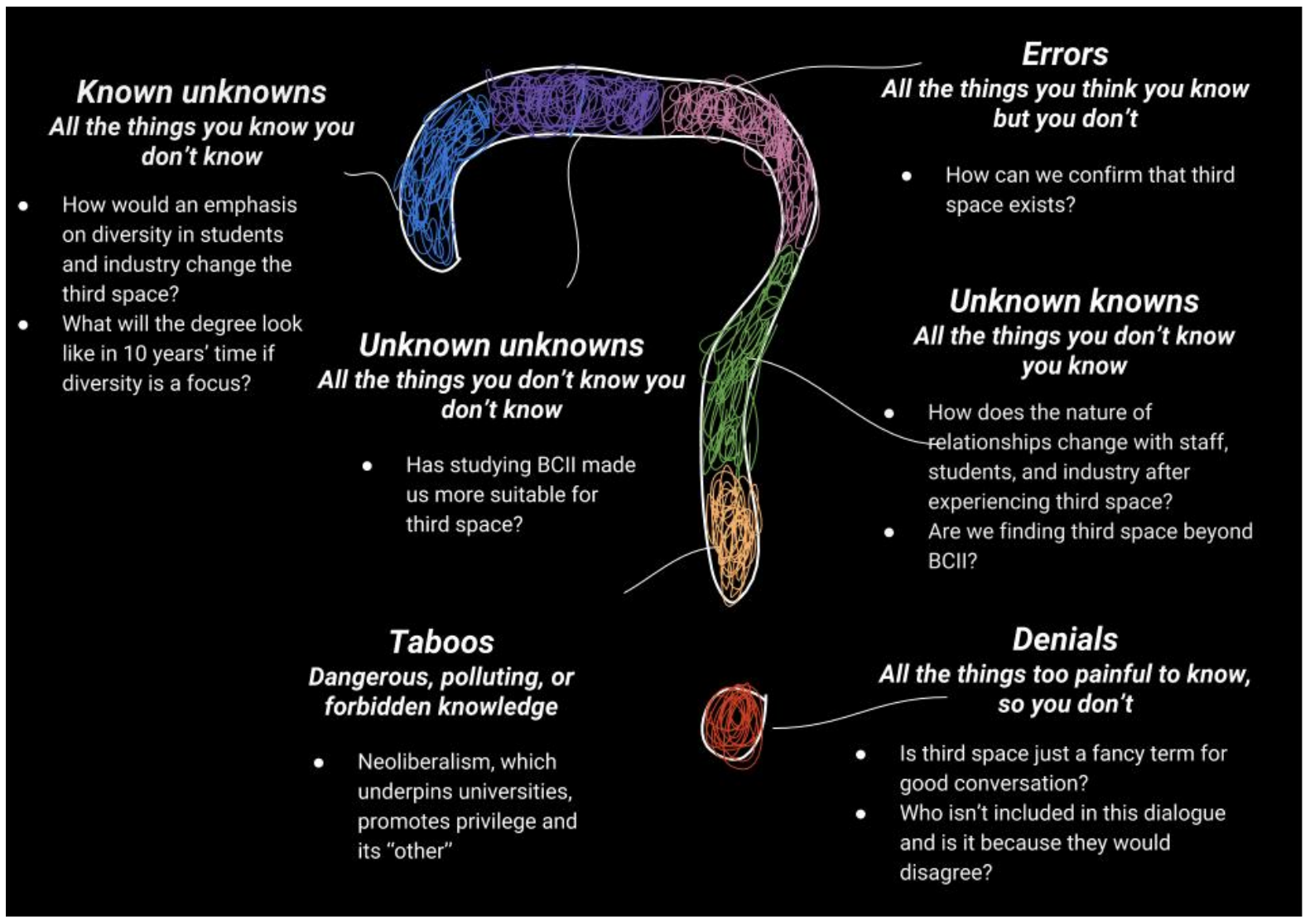

\section{CONCLUDING REMARKS}

The emergence of the independent student perspective, described above, during the final phase of our open-ended dialogical enquiry, highlights the changeable and adaptive nature of third spaces and the futility of trying to contain them, as we attempted to do with our carefully-designed dialogue methodology. It also demonstrates the benefits of "stepping in and stepping out" of such spaces, as these students did to develop an Ignorance Map and bring it back into a partnership space to enrich the dialogue. The third spaces that have emerged within the $\mathrm{BCI}$ and in our writing have enabled students to exercise agency, but staff did not attempt to control where that agency took them. We, staff and students collectively, may have become adept at creating enabling conditions for third spaces to emerge within the $\mathrm{BCII}$; however, as our student co-authors pointed out, we still have work 
to do in creating third spaces that include students from diverse backgrounds and industry partners (especially partners from the not-for-profit sector).

As we continue our mutual learning journey in our scholarship and practice, we would encourage other practitioners seeking to create enabling conditions for third spaces in their own undergraduate programs to experiment with these key elements:

- seek high-level institutional support for curriculum innovation;

- prime both students and staff to become comfortable with uncertainty (which tends to be well-supported in transdisciplinary contexts);

- encourage a pattern of "stepping into" conditions of liminality and "stepping out" into reflexive spaces where new insights can be consolidated;

- design assessment for emergent rather than pre-determined outcomes;

- incorporate real-world challenges that are reframed by students together with external stakeholders;

- encourage shared responsibilities, for example, through peer learning and student input into curriculum design; and

- include students in reflexive processes for interrogating educational practice.

In our view, these insights, and the way they came about through our dialogical partnership, speak to the transformative potential residing in a mutual learning process informed by the concepts of third space, SaP, and transdisciplinarity.

NOTES

1. Transdisciplinarity has various lineages and competing definitions which are beyond the scope of this article to fully explicate (see Gibbs, 2015; Klein, 2008, 2010; Nicolescu, 2010).

\section{NOTE ON CONTRIBUTORS}

Giedre Kligyte is a Lecturer within the Faculty of Transdisciplinary Innovation at University of Technology Sydney. In her research she explores partnership pedagogies in transdisciplinary contexts and, more broadly, change in higher education contexts, the purpose and future of universities, the nature of academic practice and academic collegiality.

Alex Baumber is a Lecturer within the Faculty of Transdisciplinary Innovation at University of Technology Sydney. Alex's research focuses on community engagement and policy options for emerging practices that offer potential environmental benefits. He is also interested in exploring transdisciplinary education practices.

Mieke van der Bijl-Brouwer is a researcher, designer and educator in human-centred and systemic design in the context of social and public sector innovation. She is currently an Associate Professor at Faculty of Industrial Design Engineering, Delft University of Technology, Netherlands.

Cameron Dowd is a recent graduate of Bachelor of Creative Intelligence and Innovation and nanotechnology at the University of Technology Sydney, Australia. He currently works as a research assistant at the University of Technology Sydney and is a co-founder of The Omni Project startup that aims to build the next generation of scholarly communications. 
Nick Hazell is a tutor within the Bachelor of Creative Intelligence and Innovation program at the University of Technology Sydney, Australia. He is also a founder and CEO of v2Food, an Australian startup exploring the plant-based meat opportunity.

Bem Le Hunte is an international author and an expert in the field of Creative Intelligence. Bem is the course director for the Bachelor of Creative Intelligence and Innovation, within the Faculty of Transdisciplinary Innovation at University of Technology Sydney, responsible for the interdisciplinary integrity and inspiration behind this flagship degree. Bem's research interests lie in the thinking, theory and practice of creativity and in trailblazing educational innovation.

Marcus Newton is a final-year undergraduate in Bachelor of Creative Intelligence and Innovation and BSC (Applied Physics) at the University of Technology Sydney, Australia. Marcus is a co-founder of and developer for The Omni Project which is building the tools for the next generation of scholarly communications.

Dominica Roebuck is a recent graduate of Bachelor of Creative Intelligence and Innovation and media arts production at the University of Technology Sydney, Australia. She currently works on new product development within Act for Peace non-profit organisation.

Susanne Pratt is based in the Faculty of Transdisciplinary Innovation, University of Technology Sydney. In her research she explores how creative practice can foster social and environmental responsibility, with an emphasis on improving environmental health and collective flourishing. She is also researching in the transdisciplinary education field.

\section{REFERENCES}

Biesta, G. (2013). The beautiful risk of education. Boulder, CO: Paradigm Publishers.

Biesta, G. (2015). What is education for? On good education, teacher judgment, and educational professionalism. European Journal of Education, 50(1), 75-87. https://doi.org/10.1111/ejed.12109

Campbell, J. (1993). The hero with a thousand faces. London: Fontana.

Cook-Sather, A., \& Alter, Z. (2011). What is and what can be: How a liminal position can change learning and teaching in higher education. Anthropology \& Education Quarterly, 42(1), 37-53. https://doi.org/10.1111/j.1548-1492.2010.01109.x

Cook-Sather, A., \& Felten, P. (2017). Ethics of academic leadership: Guiding learning and teaching. In F. Su \& M. Woods (Eds.), Cosmopolitan Perspectives on Becoming an Academic Leader in Higher Education (pp. 175-191). London: Bloomsbury.

Cook-Sather, A., Matthews, K. E., Ntem, A., \& Leathwick, S. J. (2018). What we talk about when we talk about Students as Partners. 2(2), 1-9.

https://doi.org/10.15173/ijsap.v2i2.3790

Durkheim, E., Cosman, C., \& Cladis, M. S. (2001). The elementary forms of religious life. Oxford \& New York: Oxford University Press.

Gibbs P. (2015) Introduction. In Gibbs P. (Ed.), Transdisciplinary professional learning and practice (pp. 1-6). Switzerland: Springer. 
Gutiérrez, K. D. (2008). Developing a sociocritical literacy in the third space. Reading Research Quarterly, 43(2), 148-164. https://doi.org/10.1598/RRQ.43.2.3

Hasan, H. (2014). Complexity theory. In H. Hasan (Ed.), Being practical with theory: A window into business research (pp. 49-54). Wollongong, Australia: THEORI.

Healey, M., Flint, A., \& Harrington, K. (2014). Engagement through partnership: Students as partners in learning and teaching in higher education. Higher Education Academy. Retrieved from https://www.heacademy.ac.uk/system/files/resources/engagement through partner ship.pdf

Itzchakov, G., \& Kluger, A. N. (2017). Can holding a stick improve listening at work? The effect of Listening Circles on employees' emotions and cognitions. European Journal of Work and Organizational Psychology, 26(5), 663-676. https://doi.org/10.1080/1359432X.2017.1351429

Kahn, P. E. (2014). Theorising student engagement in higher education. British Educational Research Journal, 40(6), 1005-1018. https://doi.org/10.1002/berj.3121

Kerwin, A. (1993). None too solid: Medical ignorance. Science Communication, 15(2), 166185. https://doi.org/10.1177\%2F107554709301500204

Klein, J. T. (2008). Evaluation of interdisciplinary and transdisciplinary research: A literature review. American Journal of Preventive Medicine, 35(2S), S116-S123. https://doi.org/10.1016/j.amepre.2008.05.010

Klein, J. T. (2010). A taxonomy of interdisciplinary knowledge. In R. Frodeman, J. T. Klein, \& C. Mitcham (Eds.), The Oxford handbook of interdisciplinarity (pp. 15-30). Oxford: Oxford University Press.

Labonté, R. (2011). Reflections on stories and a story/dialogue method in health research. International Journal of Social Research Methodology, 14(2), 153-163. https://doi.org/10.1080/13645579.2010.492131

Manderson, D. (1998). Some considerations about transdisciplinarity: A new metaphysics? In Transdisciplinarity: Stimulating synergies, integrating knowledge. UNESCO. Retrieved from http://unesdoc.unesco.org/images/0011/001146/114694eo.pdf.

Matthews, K. E. (2016). Students as partners as the future of student engagement. Student Engagement in Higher Education Journal, 1(1), 1-5.

Matthews, K. E., Cook-Sather, A., \& Healey, M. (2018). Connecting learning, teaching, and research through student-staff partnerships: Toward universities as egalitarian learning communities. In V. Tong, A. Standen, \& M. Sotiriou (Eds.), Shaping higher education with students: Ways to connect research and teaching. London: University College of London Press.

Matthews, K. E., Dwyer, A., Hine, L., \& Turner, J. (2018). Conceptions of students as partners. Higher Education, 76(6), 957-971. https://doi.org/10.1007/s10734-018$\underline{0257-y}$

Max-Neef, M. A. (2005). Foundations of transdisciplinarity. Ecological Economics, 53(1), 516.

McAlpine, L., \& Hopwood, N. (2009). 'Third spaces': A useful developmental lens? International Journal for Academic Development, 14(2), 159-162. https://doi.org/10.1080/13601440902970072 
Mercer-Mapstone, L., Dvorakova, S. L., Matthews, K., Abbot, S., Cheng, B., Felten, P., Knorr, K., Marquis, E., Shammas, R., \& Swaim, K. (2017). A systematic literature review of students as partners in higher education. International Journal for Students As Partners, 1(1). https://doi.org/10.15173/ijsap.v1i1.3119

Nicolescu, B. (2010). Methodology of transdisciplinarity-Levels of reality, logic of the included middle and complexity. Transdisciplinary Journal of Engineering \& Science, 1(1), 19-38.

Polk, M., \& Knutsson, P. (2008). Participation, value rationality and mutual learning in transdisciplinary knowledge production for sustainable development. Environmental Education Research, 14(6), 643-653. https://doi.org/10.1080/13504620802464841

Scholz, R., \& Steiner, G. (2015). The real type and ideal type of transdisciplinary processes: Part I-Theoretical foundations. Sustainability Science, 10(4), 527-544.

Soja, E., \& Hooper, B. (1993). The Spaces that difference makes: Some notes on the geographical margins of the new cultural politics. In M. Keith \& S. Pile (Eds.), Place and the politics of identity (pp. 183-206). USA and Canada: Routledge.

Solomon, N., Boud, D., \& Rooney, D. (2006). The in-between: Exposing everyday learning at work. International Journal of Lifelong Education, 25(1), 3-13. https://doi.org/10.1080/02601370500309436

Turner, V. (1967). The forest of symbols: Aspects of Ndembu ritual. Ithaca, New York: Cornell University Press.

Van Gennep, A. (1960). The rites of passage. Chicago: The University of Chicago Press.

Werder, C., Thomas, C., Ware, L., \& Skogsberg, E. (2010). Students in parlor talk on teaching and learning: Conversational scholarship. In C. Werder \& M. Otis (Eds.), Engaging student voices in the study of teaching and learning (pp. 16-31). Sterling, VA: Stylus.

Whitchurch, C. (2012). The concept of third space. In Reconstructing identities in higher education: The rise of 'third space' professionals (pp. 21-45). New York: Taylor and Francis.

Zepke, N. (2017). Student engagement in neo-liberal times: What is missing? Higher Education Research \& Development, 37(2), 433-446. https://doi.org/10.1080/07294360.2017.1370440 